\title{
Las Fuerzas Extrañas: Leopoldo Lugones y las Raíces de la Literatura Fantástica en el Río de la Plata
}

Se ha estudiado mucho a Leopoldo Lugones en dos de sus principales facetas literarias: la del poeta que ensanchó los límites de la poesía tradicional con Lunario sentimental (1909) y la del prosista que intentó hacer lo mismo con el "buen estilo" en La guerra gaucha (1905). Varios críticos han señalado a otro Lugones: el que escribió, con Las fuerzas extrañas, la primera colección de cuentos claramente fantásticos del Río de la Plata. ${ }^{1}$ El lector familiarizado con las mayores figuras de esta tradición-Quiroga, Borges, Bioy Casares, Cortázar-siente, al leer hoy al Lugones de 1906, una impaciencia con los personajes tiesos, los argumentos predecibles y los largos pasajes de explicación, pero también reconoce un repertorio de temas y ciertas estrategias narrativas que irían a aparecer y reaparecer en las obras fantásticas del Río de la Plata. En este ensayo me propongo analizar los elementos básicos de la ficción lugoniana a la luz de la tradición que se nutrió de. ella. Enfocaré el análisis sobre Las fuerzas extrañas, por ser el primer libro de elaboración fantástica de Lugones, y el mejor, pero me referiré también a los Cuentos fatales (1924) y a la novela El ángel de la sombra (1926), para demostrar la persistencia de temas y técnicas. ${ }^{2}$ Terminaré con algunas observaciones acerca de la influencia de Lugones sobre Quiroga, Borges, y otros maestros del género fantástico rioplatense.

\footnotetext{
${ }^{1}$ Emma Susana Speratti Piñero, "La expresión de las 'fuerzas extrañas' en Leopoldo Lugones," en Speratti Piñero y Ana María Barrenechea, La literatura fantástica en Argentina (México: Im. prenta Universitaria, 1957), pp. 1-16; Robert M. Scari, "Ciencia y ficción en los cuentos de Leopoldo Lugones," Revista Iberoamericana, 30 (1964), 163-87; Gaspar Pío del Corro, El mundo fantástico de Leopoldo Lugones (Córdoba, Argentina: Universidad Nacional de Córdoba, 1971). Para una bibliografía sobre los demás aspectos de la crítica lugoniana,' véase Alfredo Roggiano, Bibliografía de y sobre Leopoldo Lugones (México: Editorial Cultura, 1962) y "Qué y qué no del Lunario sentimental (Revista Iberoamericana, $\mathrm{n}^{\circ} 94$ (1976), pp. 71-77).

${ }^{12}$ Leopoldo Lugones, Las fuerzas extrañas, $2^{2}$ ed. (Buenos Aires: Gleizer, 1926); Cuentos fatales (Buenos Aires: Babel, 1924); El angel de la sombra (Buenos Aires: Gleizer, 1926). En adelante, me referiré a estas ediciones con las abreviaciones Fuerzas, Fatales, y Angel, respectivamente.
} 
La clasificación es un primer paso hacia el análisis. Emma Susana Speratti Piñero propone dividir los cuentos de Las fuerzas extrañas en "cientificistas", cuando su temática proviene de la ciencia, y "legendarios", cuando se basan en historias tradicionales. ${ }^{3}$ Esta clasificación es útil, pero tiene la desventaja de apoyarse sobre criterios externos. Un examen más profundo puede resultar de la comparación de los papeles de los protagonistas en varios cuentos, y de la búsqueda de analogías en sus relaciones con los otros personajes. Primero, tal examen lleva a poner de lado tres relatos de protagonista anónimo o colectivo que culminan en el fin catastrófico de una sociedad entera: "La lluvia de fuego ", "El origen del diluvio", y "Los caballos de Abdera ", Sustraídos estos cuentos, los demás empiezan a revelar semejanzas de estructura que invitan a la construcción de una especie de "cuento maestro" que reúne los elementos básicos del mundo fantástico de Lugones, como Propp lo hizo con los cuentos folklóricos rusos. ${ }^{4}$ Brevemente, este es el cuento maestro: un sabio solitario invita a un amigo (el narrador) a testimoniar el resultado de una serie de experimentos. Se sugiere que las investigaciones son diabólicas o blasfemas: violan los límites sagrados del conocimiento humano y dependen de la ayuda de seres equívocos, medio humanos. El experimento acierta, pero libera "fuerzas" terribles que destruyen al sabio, directa o indirectamente. Así, todos estos cuentos se pueblan de los avatares de tres personajes básicos: el testigo, el mago, y el intermediario entre éstos y las "fuerzas" del más allá.

\section{EL TESTIGO}

El testigo sobrevive para contar la historia al lector; por lo tanto, su papel determina las formas narrativas. Por empezar, todos los cuentos están narrados en primera persona. La mayoría adopta una estructura ya consagrada por la literatura fantástica inglesa: una introducción corta a cargo del narrador enmarca una visita al sabio en que éste cuenta las etapas anteriores de su investigación y ambos presencian el experimento final. En "Yzur", es el mago mismo quien narra su experiencia bajo el pretexto de un informe científico. El tono pseudo-científico y el tiempo que ha pasado después del desastre se encargan de proveer el distanciamento necesario. En los demás cuentos, el narrador ocupa la misma posición frente a la historia enmarcada que ocupa el lector. Pero es un lector escéptico y poco inteligente. Frente al carácter fuerte del mago, parece pasivo e ineficaz. Su falta de conocimientos científicos motiva las explicaciones largas que se intercalan: en el texto. Por ejemplo, en "La metamúsica", el narrador no sabe nada de música, y así justifica una larga explicación teórica de parte del investigador; se deja atolondrar por las palabras de éste, y así no puede impedir el desenlace fatal (Fuerzas). Como delegado del "sentido común" dentro del mundo ficticio, el narrador lugoniano comienza dudando de las declaraciones del investigador; mientras se deja convencer poco a

\footnotetext{
${ }^{3}$ Speratti Piñero, pp. 1-3.

${ }^{4}$ Vladimir Propp, Morphology of the Folktale, trad. Lawrence Scott (Austin: University of Texas Press, 1968).
} 
poco, el lector implícito se convence paralelamente. En "Un fenómeno inexplicable", el narrador reacciona ante la confesión del inglés así: "Era, a no dudarlo, un caso curioso de locura, que no excluía el más perfecto raciocinio" (Fuerzas, p. 54). Emprende la tarea de liberar al otro de la ilusión de que se ha transformado en mono, mostrándole que su sombra trazada con lápiz sobre un papel no tiene la menor semejanza con la del animal temido. Pero mientras traza la silueta, ha ido contagiándose de la convicción de su modelo:

El corazón me palpitaba, como presintiendo un infausto desenlace.

- No mire usted, dije....

Ambos palidecimos de una manera horrible. Allí ante nuestros ojos, la raya de lápiz trazaba una frente deprimida, una nariz chata, un hocizo bestial. El mono! La cosa maldita!

\section{(Fuerzas, pp. 55-56)}

Mediante este empleo del narrador, Lugones admite en la ficción un simulacro de las dudas del lector, para mejor desarmarlas.

El recurso de los "narradores encajonados" también ayuda a Lugones a acomodar extensiones vastas de espacio y tiempo dentro del cuento sin violar su forma cerrada. La acción del cuento-marco suele confinarse a una conversación de sobremesa de una noche, en una sala burguesa de Buenos Aires. Una vez que este marco ha asegurado la unidad narrativa, el cuento enmarcado puede abarcar milenios y espacios siderales. "La estatua de sal" remonta hasta el dios bíblico por una escala de narradores: el "yo" del primer párrafo conoce la historia del "peregrino", que la ha aprendido del hermano Porfirio, que la ha oído de la tradición de su convento, fundado por el protagonista, Sosistrato (Fuerzas). Sosistrato conoce la historia de la mujer de Lot por la narración del diablo disfrazado de peregrino y por la Biblia. Así, el lector salta dos abismos de tiempo: de nuestros días al tiempo de Sosistrato y los primeros cristianos; de éste a la época de Abraham y Lot.

Pero Lugones quiere evitar el exotismo. Por eso, mientras carga los tintes fantásticos de la acción narrada, estrecha los vínculos entre el narrador y el mundo ordinario. El narrador es siempre un hombre adulto pero no viejo, porteño burgués, vagamente interesado en las ciencias ocultas, pero sin mucha imaginación. En Las fuerzas extrañas, Lugones juega con identificar al narrador consigo mismo. Por ejemplo, el siniestro jardinero de "Viola acherontia" trata de "halagar visiblemente mis inclinaciones literarias" con una alusión a Shakespeare.(p. 127). El recurso se explicita en los cuatro primeros Cuentos fatales y en El ángel de la sombra. No sólo "Lugones" es el narrador de estos relatos, sino que habla de amigos reales como Baldomero Sanín Cano y José Juan Tablada (Angel), e inclusive permite a los personajes de un cuento enmarcado citar Las montañas del oro (Angel, p. 166). ${ }^{15}$

${ }^{5}$ Borges ha notado este recurso de Lugones: "Da cierta realidad a estas imaginaciones fantásticas, un procedimiento que ha encontrado muchos imitadores: el mismo Lugones es protagonista de lo que narra y en la acción intervienen amigos suyos, con su nombre verdadero." Entre los "muchos imitadores" se encuentra el mismo Borges. Jorge Luis Borges y Betina Edelberg, Leopoldo Lugones (Buenos Aires: Troquel, 1955), p. 73. 
Todos los recursos narrativos buscan construir un puente entre las "fuerzas extrañas" y la vida cotidiana del lector. Los cuentos tienden a terminar con una evocación de la presencia latente de la "fuerza" peligrosa en la "aquí ahora", que el narrador comparte con el lector. El aparato que mató al mago de "La fuerza omega" tienta al narrador en el momento de escribir: "Sobre mi mesa de trabajo, aquí mismo, en tanto que finaliza esta historia, el aparato en cuestión brilla, diríase siniestramente, al alcance de mi mano" (Fuerzas, p. 23). Una sirena prehistórica aparece en una bañadera porteña ("El origen del diluvio ", Fuerzas); el perfume que mató a Lord Carnarvon ha causado recientemente el suicidio de dos argentinos ("El vaso de alabastro", Fatales); el espejo fatal todavía "produce cierto mareo" y puede verse en el Museo Etnográfico de Buenos Aires ("Los ojos de la reina", Fatales). En tres relatos de los Cuentos fatales, "El vaso de alabastro" "Los ojos de la reina", y "El puñal", Lugones entreteje una serie que va acercándose al lector. Los tres están narrados por "Lugones", pero contienen otras narraciones enmarcadas. Los personajes de los dos últimos cuentos conocen los cuentos anteriores: han podido leerlos en las revistas donde "Lugones" los ha publicado. El narrador del cuento enmarcado de "El vaso de alabastro", el ingeniero Neale, reaparece en "Los ojos de la reina" como la víctima; el narrador secundario de "Los ojos de la reina", Mansur bey, avisa a "Lugones" de un peligro que se materializa en "El puñal". Así, el testigo de una historia viene a ser el amenzado del siguiente. El lector también se siente amenazado en la persona del narrador, su delegado. "El escuerzo", de Las fuerzas extrañas, tiene una estructura semejante. En un salón porteño, el narrador cuenta cómo una criada vieja le avisó que no matara un sapo "escuerzo"; el aviso toma la forma de la historia de otro sapo que resucitó para matar al muchacho que lo había aplastado. Hay tres tiempos: el tiempo del salón elegante, el de la niñez del narrador, y el del cuento de la criada. El muchacho del tiempo interior no hace caso del aviso de su madre, y muere; el narradormuchacho hace caso del aviso de la criada, y sobrevive; una oyente del salón, Julia, ríe de la historia del narrador adulto, y, por analogía, ella y el lector están amenazados. Todo el armazón de marcos y tiempos sirve para atrapar al lector y conseguir su participación imaginativa en la ficción.

\section{EL MAGO}

El verdadero protagonista de los cuentos de Lugones es el personaje que llamaré el mago. Siempre es un hombre; generalmente, es más viejo que el narrador, o, por lo menos, tiene más experiencia y más carácter que él. El primer cuento de Las fuerzas extrañas, "La fuerza omega", establece un patrón que moldea las narraciones posteriores. El mago de este cuento ha ganado su vida solitaria con invenciones triviales mientras buscaba "la potencia mecánica del sonido" (Fuerzas, pp. 11-12). Rechaza las teorías materialistas para internarse en el espiritualismo y las ciencias ocultas: "Sospecho, Dios me perdone, que mi amigo no se limitaba a teorizar el ocultismo, y que su régimen alimenticio, tanto como su severa continencia, implicaban un entrenamiento; pero nunca se 
franqueó sobre este punto y yo fui discreto a mi vez" (Fuerzas, p. 11). Su negativa a restringirse al materialismo ortodoxo científico lo aisla de los demás investigadores, con quienes se comunica sólo mediante libros e informes que cita libremente. Por otro lado, la "severa continencia" del protagonista dirige todas sus ansias de amor hacia el objeto de sus experimentos. Por fin logra construir un pequeño aparato que convierte las ondas sonoras en rayos destructivos. Pero resulta que el aparato sólo funciona en manos de su inventor; y cuando el sabio se encuentra muerto (iaccidentalmente?) por su propio invento, éste ha perdido su poder. El protagonista ha sido castigado por violar la frontera entre el sonido y la fuerza mecánica: muere y sus investigaciones quedan sin fruto.

La misma trama, con ligeras variantes, se despliega en "La metamúsica" (Fuerzas), "El vaso de alabastro", y "Los ojos de la reina" (Fatales). El Sosistrato de "La estatua de sal" (Fuerzas) no es un científico, pero sí un místico audaz, cuya vida de ermitaño recuerda el "entrenamiento" solitario del protagonista de "La fuerza omega"; como él sucumbe a la tentación de penetrar un misterio prohibido, y como él muere. Los investigadores de "El psychon" y "Un fenómeno inexplicable" no mueren, pero terminan en la locura (Fuerzas).

La forma novelística de $E l$ ángel de la sombra proveyó a Lugones del espacio para desarrollar más a los personajes de su obsesión. El protagonista nominal del relato es Carlos Suárez Vallejo, quien cuenta la historia a "Lugones" años después. Pero su papel se reduce a testimoniar la acción y servir de pretexto pasivo para el conflicto entre el doctor Sandoval y Luisa, el "ángel". En términos formales, Suárez Vallejo es el narrador de una historia enmarcada por la narración de "Lugones". Sandoval hace investigaciones sobre el aire del mar y las enfermedades pulmonares; Luisa es su paciente, y, además, en una vida anterior ha sido su mujer. Como el mago de "La fuerza omega", Sandoval ha concentrado su vida afectiva sobre sus investigaciones, es decir, sobre Luisa. En la vida pasada, el doctor arrojó a su mujer al mar desde las baluartes de.su castillo por amores adúlteros con la versión anterior de Suárez Vallejo, En esta vida, cuando sabe que Luisa ama a otro, la manda a una casa cerca del mar para curarse de tuberculosis, sabiendo que va a terminar en su muerte. Después dispone las cosas para que su rival lo mate en un ensayo de esgrima; deja una carta donde explica que provocó su propia muerte para castigarse.

El ángel de la sombra ejemplifica otra variante de la trama básica: puede ser que el mago no muera como resultado directo de las exploraciones prohibidas, sino que muera el intermediario que las hace posibles. Como el sabio vive para sus investigaciones, esta destrucción viene a ser un preludio o sustituto para su propia muerte. En "Yzur" (Fuerzas), el narrador revela emociones de amante hacia el mono que intenta enseñar a hablar: siente, por turno, cólera, cariño, celos, impulsos sádicos, y remordimiento. El mono muere cogido de la mano de su amo, pronunciando algunas palabras patéticas. La escena está narrada como un acto de despedida entre amantes; la emoción dominante del narrador no es la frustración de sus ambiciones científicas, sino el sentido de culpa con respecto a 
un ser querido. En "Viola acherontia", el siniestro jardinero, que "quería sus flores como un padre" (Fuerzas, p. 123), sólo consigue enloquecerlas sin remedio. En "El puñal", el mensajero que cuenta los secretos de la "Santa Fidelidad" a "Lugones" le comunica su propia muerte, al fin, con la aparición de un puñal salpicado de sangre. Profetiza una muerte semejante para el narrador si persiste en sus investigaciones (Fatales).

Dos cuentos de tema "tradicional" casi se salen del patrón: "El escuerzo", y "El milagro de San Wilfredo" (Fuerzas). En el primero, un muchacho desoye la prohibición tradicional de matar el sapo "escuerzo". El animal se reanima y se venga cubriendo al joven con una capa de escarcha que lo mata. En "El milagro de San Wilfredo", Abu Djezzar, el gobernador de Jafa, se burla de los cristianos y muestra demasiada confianza en las armas superiores de los sarracenos. La mano cortada de un cruzado martirizado por el blasfemo se reanima para matarlo. A pesar de las variantes, algunos elementos básicos vinculan estos cuentos a los demás del libro: la independencia orgullosa del protagonista, su violación de un límite sagrado, y su castigo. Los protagonistas de todos estos cuentos buscan el conocimiento prohibido para gozar su propia destrucción.

\section{EL INTERMEDIARIO}

Los narradores de la ficción lugoniana pertenecen al mundo cotidiano del buen sentido. Los protagonistas que llamo "magos" se atreven a explorar los límites de este mundo, pero están condenados a quedar en este lado. Por eso necesitan intermediarios, seres ambiguos que habitan la frontera de lo conocible. En el caso más sencillo, el intermediario es un aparato descrito en términos seudo-científicos. No asoman en Lugones las máquinas monstruosas de la ciencia-ficción ortodoxa: conforme al propósito de "suprimir en lo posible la materia" (Fuerzas, p. 11), los instrumentos de sus magos decepcionan con su aspecto trivial:

Confieso que el aparato nos defraudó. La relación de magnitudes forma de tal modo la esencia del criterio humano, que al oir hablar de fuerzas enormes habíamos presentido máquinas grandiosas. Aquella cajita redonda, con un botón saliente en su borde, parecía cualquier cosa menos un generador de éter vibratorio.

("La fuerza omega ", Fuerzas, p. 19)

Así, en "La metamúsica", el lector tiene que aceptar la potencia destructiva de "una caja como de dos metros de largo, enteramente parecida a un féretro" (Fuerzas, p. 87); en "El psychon", la de un "poco de agua clara" encerrada en un vaso (Fuerzas, p. 168). La vinculación de una "fuerza" peligrosa a un instrumento de aspecto ordinario contribuye al efecto inquietante de estos cuentos.

La relación entre el investigador y su intermediario se vuelve más dramática cuando éste aparece en la forma de un ser vivo. Según la teoría propuesta en "Ensayo de una cosmogonía" (Fuerzas), no sólo el hombre, sino toda la escala vital deriva del pensamiento, la forma más pura de la energía. Invirtiendo el 
darwinismo, Lugones teoriza que espíritus racionales como el hombre siempre han existido, engendrando imitaciones más o menos fieles en la materia: los monstruos de la fábula, los animales, las plantas. El animal y la planta representan otros momentos en el flujo y reflujo entre la materia y el pensamiento, y, por eso, pueden traer al hombre noticias de esas regiones intermedias. En "Yzur" (Fuerzas), el narrador intenta restaurar a un mono la capacidad lingüística que sus antecesores han rechazado, pero su violación de la barrera entre las especies sólo le proporciona algunas palabras en el momento de la muerte del animal. En "Viola acherontia", el jardinero sueña en convertir unas violetas en "la flor de la muerte" (Fuerzas, p. 121). Compara sus flores a muchachas histéricas, las quiere "como un padre" (p. 123), habla de "su cerebro", y las llama "seres inversos" (p. 125). Cuando está a punto de conseguir su deseo, las violetas, sobreexitadas por las "escenas crueles" que su "padre" les ha obligado presenciar, se vuelven locas y no pueden hacer más que lanzar débiles aves semi-humanos.

El animal es el reflejo invertido del hombre, su familiar, su doble. En "Un fenómeno inexplicable" (Fuerzas), un fragmento de la personalidad del protagonista inglés, separado de él por experimentos temerarios con el misticismo oriental, se concretiza en la sombra de un mono que toma el lugar de la sombra del hombre. El mono es a la vez familiar y ajeno: el inglés lo ve siempre consigo, pero no puede comunicarse con él. El hombre ha perdido el sentido de la unidad de su ser hasta el punto de que, cuando estrecha su propia mano, siente que es de otro. Lugones tenía bastante interés en los temas de la esquizofrenia y del doble para tratarlos otra vez en un cuento del Lunario sentimental, "La novia imposible":

...Tenía un amigo fantástico, un chico semejante a mí, creado por mí; conversaba con él, nos referíamos nuestros percances, nos disgustábamos a veces. Para objetivar aquella fantasía, figurábame que mi mano izquierda era la suya, y así experimentaba el placer de estrechársela. Un día que me herí en aquella mano, no sentí. dolor, pues el herido era el otro.... ${ }^{6}$

Gaspar Pío del Corro ha señalado la fascinación de Lugones con "la frontera entre el rugido y la palabra, esto es, entre la animalidad y la condición humana"." El animal con rasgos humanos inspira más terror que el animal definitivamente bestial, por feroz que sea, porque su ambigüedad arroja una duda sobre la identidad del hombre. La muerte del muchacho de "El escuerzo" se siente como más terrible porque se representa como la venganza de un sapo con rencores humanos. Del mismo modo, el narrador de "La lluvia de fuego" no comprende plenamente la destrucción de su ciudad hasta que oye a los leones "con un

${ }^{6}$ Leopoldo Lugones, Lunario sentimental, en Obras poéticas completas, prólogo de Manuel Pedro Obligado, $2^{\mathrm{a}}$ ed. (Madrid: Aguilar, 1952), p. 305.

${ }^{7}$ Pío del Corro, p. 29. 
desvarío humano en los ojos" lanzar rugidos que "tenían una evidencia de palabra" (Fuerzas, pp. 39-40). El clímax de "El origen del diluvio" se subraya con el descubrimiento de una sirena-ambiguo pez-mujer-en la palangana del cuarto bonaerense (Fuerzas).

"Los caballos de Abdera" (Fuerzas) se estructura alrededor de dos momentos en que la barrera bestia-hombre está superada. Los ciudadanos de Abdera han intentado dotar sus caballos de todos los rasgos humanos posibles. Irónicamente, sólo han podido asumir las más "bestiales" costumbres humanas: la vanidad, el infanticidio, la rebelión, el gusto por la carne, y la borrachera. Un día los caballos se sublevan, matan a muchos de sus amos, y asedian a los demás en la fortaleza. Un león gigantesco aparece para hacer huir a los caballos; resulta ser Hércules vestido con la piel de un león vencido. El cuento equilibra dos movimientos antitéticos: los hombres de Abdera neciamente regalan dones humanos a sus animales, y estos dones casi obran su destrucción; Hércules toma de un animal la melena, los colmillos, y las garras que le ayudan en su ascendencia a dios. El caballo semi-humanizado resulta peor que una bestia; el falso león revela a un héroe semi-divino.

El intermediario tiene que ser bastante semejante al investigador y al narrador para comunicarse con ellos; al mismo tiempo, tiene que diferir lo bastante como para penetrar en las regiones prohibidas. Por eso, un intermediario común en los relatos de Lugones es la mujer. En la ficción lugoniana, son los hombres los que narran o explican sus teorías; la mujer se ve desde afuera como un medio, un ser mitad humano, mitad "ángel". Como a los animales, la posición ambigua de la mujer casi siempre les trae la muerte a ella y al que la ama. Por ejemplo, la mujer de Lot ha sido preservada durante siglos como una "Estatua de sal" (Fuerzas). El ermitaño Sosistrato la despierta para que pueda morir y liberarse. Como recompensa, la obliga a decirle el secreto de la ira de Dios, y la revelación lo mata. En "El milagro de San Wilfredo", el futuro santo mata a su esposa inocente en un arranque de celos. Su arrepentimiento, sim. bolizado por un yelmo blanco que recibe misteriosamente en la tumba de la inocente, lo purifica para sufrir el martirio y obrar el milagro del título.

En Cuentos fatales y El ángel de la sombra, Lugones intenta reforzar la autoridad misteriosa de sus mujeres haciéndolas provenir de un pasado remoto o de un oriente exótico. La Hat-shep-sut de "El vaso de alabastro" se hace enterrar con un vaso de perfume mortífero que mata al arqueólogo que viola su tumba; la Sha-it de "Los ojos de la reina" tiene ojos fatales que hacen suicidarse a todos sus amantes, y es además reencarnación de Hat-shep-sut; la "Santa Fidelidad". de los drusos, descrita en "El puñal", se basa en la adoración de la mujer:

\footnotetext{
${ }^{18} \mathrm{~A}$ los animales-hombres de Las fuerzas extrañas pueden añadirse "La yegua bruja" y "El tigre capiango" de los Romances de Río Seco [Obras poéticas completas] y el perro antropófago de "Vívac" en La guerra gaucha (1905; rpt. Buenos Aires: Centurión, 1950), pp. 173-82.
} 
- Sepa usted, dijo [el mensajero de la Santa Fidelidad], que nuestra veneración por la mujer proviene de atribuirle como causa fatal toda la dicha y toda la desventura...

Por eso estamos bajo la potestad de la Mujer, que, ángel o demonio, es la puerta del Paraíso y del Infierno...

...para el perfecto caballero, amar es morir.

Por esto sólo alcanza la inmortalidad quien domina el amor de la mujer...."

(Fatales, pp. 85-86)

Luisa desempeña un papel semejante en El ángel de la sombra. Sabe, por instinto, que reencarna a una dama del medioevo provenzal. Desecha su nombre de bautismo y toma el de la dama; ve a los ángeles, escucha voces, y profetiza la muerte de otras personas y de sí mismo "como si otra persona recordara y hablara en mí" (p. 46).

El aparato ocultista de los dos últimos libros relega a las mujeres a una esfera tan espiritual que Lugones necesita crear segundos intermediarios para interpretar sus revelaciones. A este grupo pertenecen el muchacho egipcio, Mustafá, que explica las tradiciones faraónicas al Mr. Neale de "El vaso de alabastro"; Mansur-bey, el protector de Sha-it en "Los ojos de la reina"; el enviado de la "Santa Fidelidad" en "El puñal" (Fatales); el Ibrahim Asaf y el negro Blas de El ángel de la sombra. Vienen de una raza más primitiva y, por eso, en más estrecha comunicación con las regiones extrarracionales. Hay muchas semejanzas entre estos mensajeros y los protagonistas de "El secreto de don Juan" y "Agueda" (Fatales). Don Juan y el bandido Nazario Lucero tienen una belleza equívoca de piel oscura y ojos azules; emanan una atracción animal, pero dominan una sabiduría milenaria; viven aislados de la sociedad como criminales, pero adoran a la mujer. Irrumpen en la tranquila vida burguesa de los demás personajes para traer la destrucción, pero también la revelación de lo que puede ser la pasión verdadera.

Un hilo une las diversas manifestaciones del intermediario en la ficción lugoniana: para el protagonista, es un ser prohibido y ajeno, animal o mujer o extranjero; y con el conocimiento trae el erotismo y la muerte.

\section{EL DESARREGLO DE LOS SENTIDOS}

En el "Ensayo de una cosmogonía", que cierra Las fuerzas extrañas, y en los largos discursos científicos prodigados en sus cuentos, Lugones proporciona al lector una teoría de la estructura del universo capaz de explicar-por lo menos dentro de la ficción-los acontecimientos fantásticos de sus relatos. Según esta teoría, todos los fenómenos del universo son formas de la energía pura: la del pensamiento. La materia, los seres vivos, el hombre, la energía mecánica, el sonido, la luz, el tiempo y el espacio son porciones de un espectro cósmico que se abre como un abanico cuando el pensamiento se diferencia en el desarrollo 
cósmico. Un día van a integrarse otra vez en una unidad matriz de nuevos universos. Los protagonistas de Lugones se atreven a adelantar este proceso cíclico, a convertir un orden del ser en otro: el sonido en luz, por ejemplo. Pero un hombre sole no puede barajar así las formas constituyentes del universo sin liberar fuerzas que destruyen a él o a su obra.

Entonces, para Lugones, la sinestesia es más que un recurso poético ${ }^{9}$ es una teoría cosmogónica y una fuente de argumentos fantásticos. Forzar el registro sagrado de la energía cósmica trae la muerte como castigo. Así pecan los habitantes de las ciudades malditas de "La lluvia de fuego" (Fuerzas). En un esfuerzo para estimular el placer, empujan cada sensación hasta el límite en que se confunde con las demás sensaciones. Al lado de un "equívoco mancebo"--hombre-mujer-aparecen carteles anunciando "ayuntamientos de lagartos con cisnes; un mono y una foca; una doncella cubierta por la delirante pedrería de un pavo real" que recuerdan los bestia-hombres de "Un fenómeno inexplicable" y "El origen del diluvio" (Fuerzas, p. 52). Los sentidos se aguzan: las cortesanas descubren sus senos "sudando perfumes"; un bailarín derrama polvos de colores que forman cuadros obscenos; cobertores suaves estimulan el deseo sexual (p. 52); el creador de una nueva salsa o de un beso original merece "un busto municipal" (p. 29). La sociedad de Sodoma y Gomorra parece haberse organizada para cumplir el "long, immense et raisonné dérèglement de tous les sens" recetado por Rimbaud. ${ }^{10}$ No son las únicas criaturas lugonianas en hacerlo. El mago de "La fuerza omega" intenta despertar "la potencia mecánica del sonido" (Fuerzas, p. 12). El Juan de "La metmúsica" logra convertir la "armonía de las esferas" en luz, sin prever que esta luz traerá el calor que lo quemará vivo. Dr. Paulin condensa el pensamiento en un gas, "El psychon", que, respirado como un perfume, produce la locura. El jardinero de "Viola acherontia" busca criar flores de perfume mortífera (Fuerzas). En "El vaso de alabastro", los químicos de la reina Hat-shep-sut realizan esta ambición: preservan un perfume tres mil años para dar la muerte al violador de la tumba real (Fatales).

La visión es el sentido más humano, pero es también el sentido con más capacidad de engañar. En Lugones, el espejo representa la vista como ilusión destructora. El joven neurótico de "La novia imposible" teme a los espejos: ${ }^{10}$

- Estás enfermo.

-No, un poco débil y nada más. Sé que estoy muy cambiado; pero no importa; he mandado quitar todos los espejos.

${ }^{9}$ Un ejemplo de la sinestesia en la poesía de Lugones es el "largo suspiro violeta" de "Tentación", en Los crepúsculos del jardín, Obras poéticas completas, p. 117.

${ }^{10}$ Arthur Rimbaud, "Lettre à Paul Demany, le 5 de Mai, 1871" ("Lettre du voyant"), en Lettres de la vie littéraire d'Arthur Rimbaud (1870-1875), ed. Jean-Marie Carré (París: Librarie Gallimard, 1931), p. 62. El énfasis está en el original.

${ }^{11}$ Leopoldo Lugones, Obras poéticas completas, p. 307. En la fábula "Mr. Bergeret" de Filosoficula, Lugones atribuye el origen de las ideas de lo sobrenatural, el doble, y dios a la invención del espejo (Buenos Aires: Babel, 1924), p. 111. 
Sin embargo, no advierte que la novia blanca y perfecta que goza cada noche en el estanque es el reflejo de la luna sobre el espejo del agua; prefiere morir de frío abrazado a su ilusión. En "Los ojos de la reina", la mirada de Hat-shep-sut, conservada por milenios en la superficie de un espejo, produce deseos irresistibles de suicidio en los dos jóvenes arqueólogos que abren su tumba (Fatales). El mensajero misterioso de "El puñal" parece a la vez presente y distante, "como si estuviera constantemente acercándose sin llegar, desde el fondo de un espejo" (Fatales, p. 74). Muestra al narrador un puñal cuya hoja pulida refleja los pensamientos, pero no refleja al enviado; cuando este puñal reaparece salpicado de sangre, su reflejo apagado simboliza la muerte de su dueño.

Normalmente, cuando sospechamos que la vista nos engaña con "espejismos", podemos recurrir a los otros sentidos. El inglés de "Un fenómeno inexplicable" afirma que tiene la sombra de un mono, aunque a los ojos del narrador presenta el perfil de un hombre de "craneo elevado" y "nariz recta" (Fuerzas, p. 54). Pero cuando el narrador traza el perfil de su huésped sobre una hoja de papel "sin levantar la mano", produce el retrato de un mono (Fuerzas, pp. 55-56). La evidencia del tacto desmiente la evidencia visual. El hombre que se ha atrevido a desencajar los sentidos ya no puede encontrar la verdad entre sus mensajes contradictorios.

Pero si son peligrosas las confusiones de los sentidos, lo es mucho más la confusión de las estructuras primarias del pensamiento: el tiempo y el espacio. En 1921 Lugones publicó El.tamaño del espacio, uno de los primeros comentarios en cualquier lengua sobre las teorías de Einstein. ${ }^{12}$ Estas especulaciones espaciotemporales ya asoman en Las fuerzas extrañas. Por ejemplo, un ser que parece tener dimensiones fijas se expande o se contrae; o el contenido de un receptáculo herméticamente cerrado se escapa o se aumenta, sin que éste haya sido abierto. En "La fuerza omega", el mago apunta, por descuido, su aparato de rayos destructivos de sonido hacia su propia cabeza. El horror de la escena final deriva del contraste entre el cráneo intacto del científico muerto y el perfecto vaciado de su "sustancia cerebral", convertido en "una capa gasosa" que cubre la pared (Fuerzas, p. 23). Lugones muestra un asco verdaderamente sartreano hacia las sustancias viscosas, de tamaño y forma inestables. En "El escuerzo", los poderes sobrenaturales del pequeño sapo se manifiestan en su capacidad para "hincharse por grados...hasta triplicar su volumen". Al mismo tiempo que se hincha, penetra la caja cerrada que protege al hijo de la viuda, y lo mata helándolo en un "baño de escarcha" (Fuerzas, p. 76). En "El milagro de San Wilfredo" también, la muerte cubre el cuerpo joven del santo como una capa de escarcha (Fuerzas, pp. 65-66). En "El origen del diluvio", el espíritu describe así a los primeros seres inteligentes:

Esbozos de hombres, más bien que hombres propiamente dicho, o especies de monos gigantescos y huecos, tenían la facultad de reab-

${ }^{12}$ Leopoldo Lugones, El tamaño del espacio (Buenos Aires: "El Ateneo," 1921). 
sorberse en esferas de gelatina o la de expandirse como fantasmas hasta volverse casi una niebla. Esto último constituía su tacto, pues necesitaban incorporar los objetos a su ser, envolviéndolos enteramente para sentirlos....Eran perversos y formidables....Sabían emanar de sus fluidos organismos, seres cuya vida era breve pero dañina, semejantes a las carroñas con los gusanos.

\section{(Fuerzas, p. 98)}

Al final del cuento uno de estos seres aparece en la sala de la medium como "una masa tenebrosa" con "tentáculos" que crece "como un globo" y amenaza envolver a los concurrentes. Cuando el narrador enciende la luz, el globo estalla, cubriendo a los testigos con "un lodo heladísimo" y dejando en la palangana a "una pequeña sirena muerta" (Fuerzas, pp. 104-105). El perfume que sale de "El vaso de alabastro" para matar a Lord Carnarvon (Fatales), y "El psychon" que escapa del vaso roto para difundir la locura en el laboratorio del Dr. Paulin (Fuerzas) pueden añadirse a la lista de sustancias equívocas en la obra de Lugones.

Otra distorsión espacial que fascinaba a Lugones era la que él llamaba la "bilocación", o sea, la presencia de un ser en dos lugares separados durante el mismo instante del tiempo. ${ }^{13}$ Pueden tomarse como variantes de la bilocación la acción a distancia y la travesía de distancias inmensas en una fracción de segundo. Por ejemplo, en "La estatua de sal", el peregrino afirma que las oraciones de los santos ermitaños "contenían con su esfuerzo la vacilante bóveda de los cielos próxima a desplomarse sobre los pecados del mundo" (Fuerzas, p. 148). El investigador Juan osa tocar fuera de su contexto "la octava del sol", y la fuerza solar salta el espacio para quemarlo vivo (Fuerzas). El clímax del "Milagro de San Wilfredo" es un ejemplo claro de bilocación: en el momento en que el primer cruzado gana las murallas de Jerusalén (como Wilfredo ha profetizado), la mano cortada del mártir se agarra del cabello del gobernador blasfemo de Jafa, y éste muere en una convulsión. ${ }^{14 !}$ En "El puñal", el narrador sospecha que su visitante está en su cuarto, sólo en aparencia, cuando nota que el viento de la ventana no puede mover una cinta en su mano. Para anunciar su muerte, el desconocido hace aparecer, de repente, en el cuarto del narrador, un puñal que ha llevado consigo a Afganistán. De nuevo la música sirve de intermedio: el puñal cae detrás de un piano en que se toca Beethoven (Fatales). En El ángel de la sombra, los vínculos afectivos posibilitan la comunicación a través de las distancias. Luisa recibe un anuncio cuando su amiga Flora se muere en el

\footnotetext{
${ }^{13}$ Lugones utiliza el término "bilocación" para caracterizar un suceso fantástico de "Talión", en La guerra gaucha, p. 277.

${ }^{14} \mathrm{El}$ cuento termina con un enigma: el lector lee que los cristianos veneraron "al caballero del blanco yelmo que padeció muerte de cruz entre los infieles el 12 de julio del año 1099 de Cristo" (Fuerzas, p. 68). Pero el autor ha tomado cuidado en indicar que Wilfredo murió el 15 de junio; el que muere un mes después es Abu Djezzar. ¿Será que quiere sugerir al lector que el infiel y el mártir ambos hacen posible el milagro, que son dobles uno del otro, que la muerte de Wilfredo no acaba hasta que lleve consigo a su pareja diabólica?
} 
hospital; el reloj de Suárez Vallejo se pára cuando su amada cae enferma; en el momento en que Suárez muere en Lisboa, el narrador, "Lugones", oye un estallido y ve una lista azul ondular y desaparecer en la oscuridad de su cuarto, en Buenos Aires.

La superación del tiempo se presenta en la ficción de Lugones como el triunfo del destino. Ciertos lugares, ciertos objetos, ciertas razas tienen el poder (o la maldición) de hacer acontecer otra vez sucesos trágicos del pasado, como si no valiera el tiempo transcurrido. En "La estatua de sal", el encuentro del ermitaño con la mujer castigada entre las ruinas de Sodoma y Gomorra, reintegra una pareja implicada en los pecados de las ciudades malditas, y los siglos separadores desaparecen:

El pasado acababa de desvanecerse en él, como si el viento de fuego hubiera barrido su alma. Y sólo este convencimiento ocupaba su conciencia: la mujer de Lot estaba alli? El sol descendía hasta las montañas...Era como una resurrección del castigo, reflejándose por segunda vez en las aguas del lago amargo. Sosistrato acababa de retroceder en los siglos. Recordaba. Había sido actor en la catástrofe. Y esa mujer... jesa mujer le era conocida! (Fuerzas, p. 153)

La conjunción de las mismas circunstancias hace inevitable el mismo desenlace, y Sosistrato cae víctima del pecado de curiosidad que condenó a la mujer de Lot. La repetición misteriosa siempre surge de una identidad más profunda que se basa en la herencia racial o la reincarnación. Por ejemplo, Mustafá, en "El vaso de alabastro", sabe los secretos de las tumbas faraónicas ('ia través de tres mil años!) sólo por ser egipcio (Fatales). Mansur-bey, el egipcio aristocrático de "Los ojos de la reina", inclusive puede leer los jeroglíficos; por ellos sabe que Sha-it, una muchacha de "abolengo dinástico", reincarna a Hat-shep-sut, rediviva, para liberar a Egipto otra vez de sus dueños extranjeros (Fatales, pp. 41-42). La pureza de raza se refuerza con la lealtad a sociedades secretas milenarias. Mansur-bey ("Los ojos de la reina") pertenece a "la masonería de Menfís"; el mensajero desconocido ("El puñal") viene de "la Santa Fidelidad de los Asesinos", que exige sangre drusa sin mezcla. El "Lugones" narrador se siente atraído al estudio de la "Fidelidad" porque su sangre española tiene una corriente árabe (Fatales, pp. 71-72). En El ángel de la sombra, los temas favoritos reaparecen. Otro miembro de la Santa Fidelidad, Ibrahim Asaf, viene del oriente para explicar al narrador y a los lectores el significado secreto del desenlace de la novela: es la repetición de una tragedia del siglo XII en Provenza, con actores reencarnados. En "El secreto de don Juan" (Fatales), un personaje literalmente inmortal aparece en el Buenos Aires actual. Unos pocos seres marcados por el destino escapan a las leyes ordinarias del tiempo y del espacio. En la mayoría de los cuentos de Lugones quien viola esas leyes constituyentes del universo es un sabio solitario; en "La lluvia de fuego" y "Los caballos de Abdera", es una ciudad; en "El origen del diluvio", son todos los habitantes del mundo en una etapa de su evolución (Fuerzas). Pero una misma 
temática y una, obsesión con el conocimiento que entraña la muerte une toda la ficción de Lugones.

Los protagonistas de Lugones pertenecen al linaje del Fausto de Goethe, del Frankensteinide Mary Shelley, y de los investigadores audaces de Poe. A fines del siglo diexinueve la tradición del romanticismo negro, vigorizada por la moda de las ciencias ocultas, llegó a constituir todo un género de literatura popular - con Arthur Conan Doyle, Bram Stoker, Jules Verne, y H. G. Wells-, de la cual iban a desprenderse la ciencia-ficción y la película de horror con su "científico loco" en el siglo veinte. En el Río de la Plata proliferaban traducciones de estas obras, $\mathrm{y}$ autores como Eduardo Holmberg escribieron los primeros ejemplos nativos. ${ }^{15}$ Visto desde la perspectiva de la literatura fantástica mundial, Leopoldo Lugones toma un lugar secundario: si su estilo es siempre bien cuidado, sus temas son derivativos, sus personajes tiesos y sus argumentos poco variados. Sin embargo, Las fuerzas extrañas es uno de los primeros libros latinoamericanos que se dedica enteramente a explotar, con voluntad artística, la rica vena de la literatura fantástica europea. En los últimos párrafos de este ensayo voy a dibujar rápidamente cómo ciertos elementos de la ficción de Lugones destacados en el análisis anterior fueron aprovechados por algunos de los grandes maestros de la ficción fantástica rioplatense.

Horacio Quiroga fue un gran admirador de la poesía de Lugones desde su juventud en Salto, Uruguay; cuando se estableció en Buenos Aires, tomó al poeta ya consagrado como maestro y amigo. Quiroga descubrió Misiones por primera vez como secretario de Lugones durante el viaje para compilar materiales sobre $E l$ imperio jesuítico (1903); en uno de sus primeros relatos fantásticos, "Los perseguidos" (1905), Lugones figura como un personaje importante. ${ }^{16}$ Durante la primera residencia de Quiroga en Buenos Aires (19021910), los cuentos que va publicando en revistas y periódicos se apoyan en la misma temática que obsesionaba a Lugones en este período: los hombresanimales y animales-hombres, sobre todo los monos ("El lobison", "El mono ahorcado", "El mono que asesinó"), los científicos que exploran lo prohibido ("El retrato", "El hombre artificial"), y la reincarnación ("El mono que asesinó"). ${ }^{17}$ Son temas que van a hacerse más y más importantes en la obra posterior de Quiroga, sobre todo el de las relaciones ambiguas entre hombres y

\footnotetext{
${ }^{15}$ Nicolás Cócaro, "La corriente literaria fantástica en la Argentina," prólogo a Cuentos fantásticos argentinos, ed. Cócaro (Buenos Aires: Emecé, 1960). Para esta sección consulté también G. R. Thompson, ed., The Gothic Imagination: Essays in Dark Romanticism (Pullman, Washington: Washington State University Press, 1974) y Montague Summers,' The Gothic Quest: a History of the Gothic Novel (London: The Fortune Press, 1938).

${ }^{16}$ Emir Rodríguez Monegal, El desterrado: vida y obra de Horacio Quiroga (Buenos Aires: Losada, 1968); Horacio Quiroga, "Los perseguidos", en Selección de cuentos, prólogo y selección de Emir Rodríguez Monegal (Montevideo: Misterio de Instrucción Pública y Previsión Social, 1966), tomo I, pp. 28-58.

117'Horacio Quiroga, Novelas cortas, 1908-1910 y Cuentos, 1905-1910, tomos 1 y 4 de Obras inéditas y desconocidas, ed. Angel Rama (Montevideo: Arca, 1967-8).
} 
animales. Al comparar dos cuentos que narran intentos de hacer hablar a un mono- "El mono ahorcado" de Quiroga (1907) ${ }^{18}$ y "Yzur" de Lugones (Fuer$z a s)$ - se ven las cualidades de Quiroga que le ayudaron a superar a su maestro. El esfuerzo para hablar mata al mono lugoniano, que sólo llega a decir, "Amo, agua. Amo, mi amo..." en el momento de su muerte, palabras patéticas que subrayan la distancia entre el hombre y el animal y la clara subordinación de uno al otro (Fuerzas, p. 144). En cambio, Quiroga prescinde del desenlace fantástico-su mono se ahorca antes de llegar a hablar-y, aunque sugiere que su mono había adquirido características humanas, no encubre las ambigüedades, como hace Lugones. Quiroga renuncia a una narración privilegiada desde afuera para adentrarse mucho más en los sentimientos del mono, prefigurando así cuentos como "La insolación" y "El alambre de púa", escritos completamente desde el punto de vista de animales. ${ }^{19}$ Cuando Horacio Quiroga llegó a Buenos Aires en 1902, estaba listo ya para ir más allá de la influencia poeiana; en el período de su primera asociación, Lugones le sirvió de maestro en un esfuerzo por situar sus cuentos en un ambiente americano y contemporáneo, para explorar las implicaciones metafísicas de nuevos descubrimientos científicos, y para aprovechar la tradición fantástica europea.

Borges también ha reconocido su deuda a Lugones. ${ }^{20}$. Muchos temas típicamente borgianos ya se encuentran asociados en la ficción de Lugones: la anulación del tiempo o del espacio; las sociedades secretas; los espejos; los dobles; la luna; el inmortal; la repetición de un drama fatal en siglos diferentes; y tal vez otros. Como Lugones, Borges prefiere situar sus cuentos en el Cercano Oriente o en la India, es decir, en las civilizaciones exóticas colonizadas por el Imperio Británico; le gusta reconocer su deuda a la ficción fantástica inglesa introduciendo personajes ingleses como el ingeniero de ferrocarril Herbert Ashe, que recuerda al ingeniero Neale de Cuentos fatales. Borges maneja las formas narrativas más hábilmente que Lugones. Sabe sugerir varias explicaciones para los hechos fantásticos, sin elegir ninguna. No necesita matar a sus personajes para crear efectos sombríos, porque ha encontrado un destino peor: deja al protagonista en el momento en que descubre que sus problemas forman parte de una regresión infinita que no tiene solución lógica posible. Otros autores de ficción fantástica en el Río de la Plata tienen deudas con Lugones. Por ejemplo, el Castel de Adolfo Bioy Casares elabora un "plan de evasión" por el "desarreglo de los sentidos", que recuerda el que padecen los protagonistas de "Un fenómeno

\footnotetext{
${ }^{18}$ Horacio Quiroga, Cuentos, 1905-1910, pp. 52-5.

"1b Horacio Quiroga, "La insolación" y "El alambre de púa", en Cuentos de amor de locura y de muerte, $3^{\mathrm{a}}$ ed. (Buenos Aires: Babel, 1925), pp. 83-92 y 93-108.

${ }^{20}$ Jorge Luis Borges y Betina Edelberg, Leopoldo Lugones; Jorge Luis Borges, “A Leopoldo Lugones", prólogo de El hacedor (Buenos Aires: Emecé, 1960).

${ }^{21}$ Jorge Luis Borges, "Tlön, Uqbar, Orbis Tertius", en Ficciones (1941; rpt. Buenos Aires: Emecé, 1956), pp. 13-36.
} 
inexplicable", "La metamúsica" y "La lluvia de fuego" (Fuerzas) ${ }^{22}$

Como diría "Pierre Menard", Borges y sus sucesores desarrollaron los temas de Lugones con tanto éxito que los cuentos del originador parecen derivativos al lector de hoy. Pero la historia literaria no puede pasar por alto la contribución de Leopoldo Lugones: introdujo en la ficción rioplatense precisamente los temas y complejos de temas de la tradición fantástica europea que iban a estimular la imaginación de narradores mejores que él.

Yale University

PAULA SPECK

${ }^{22}$ Adolfo Bioy Casares, Plan de evasión, $2^{\text {a }}$ ed. (Buenos Aires: Galerna, 1969). 